\title{
A configuração e a distribuição espacial seletiva e desigual das redes de comunicação no território do Vale do Rio Pardo-RS
}

\author{
Diana Filipina Anton*
}

Rogério Leandro Lima da Silveira** Grazielle Betina Brandt***

Submissão: $24 / 08 / 2021 \quad$ Aceite: $28 / 11 / 2021$

\begin{abstract}
Resumo
Com os avanços tecnológicos, há uma crescente agenda de pesquisas sobre a mídia, seus impactos e transformações, considerando as plataformas e dispositivos que, continuamente, ganham mercado e influenciam o comportamento do consumidor da informação. Interessa-nos, neste artigo, analisar como as redes de comunicação se distribuem pelo território do Vale do Rio Pardo-RS. Para realizar a análise, utilizamos dados secundários provenientes de órgãos e instituições oficiais, como a ADI-RS, a Adjori-RS, a Anatel e a Teleco. Quando observamos o território do Vale do Rio Pardo, percebemos que a configuração e a distribuição espacial das redes de comunicação incorporam conteúdos de ciência, técnica, informação e, também, de capital. Ao mesmo tempo, a expansão do meio técnico-científico-informacional, nas condições atuais, se faz acompanhada da expansão da pobreza estrutural e da exclusão digital, uma vez que aquele também é social.
\end{abstract}

Palavras-chave: Território. Espacialidades. Redes de comunicação. Dinâmica Regional.

\section{The configuration and selective and unequal spatial distribution of communication networks in the territory of the Rio Pardo Valley-RS}

\begin{abstract}
With the technological advances, there is a growing agenda of research on the media, its impacts and transformations, considering the platforms and devices that continually gain market and influence the behavior of the information consumer. In this article we are interested in analyzing how the communication networks are distributed throughout the territory of Vale do Rio Pardo-RS. To carry out the analysis, we used secondary data from official organs and institutions, such as ADI-RS, Adjori-RS, Anatel and Teleco. When we observe the territory of the Rio Pardo Valley, we notice that the configuration and spatial distribution of the communication networks incorporate contents of science, technique, information, and also capital. At the same time, the expansion of the technical-scientific-informational environment, under current conditions, is accompanied by the expansion of structural poverty and digital exclusion, since the former is also social.
\end{abstract}

Keywords: Territory. Spatialities. Communication networks. Regional dynamics.

\section{Introdução}

Na análise da configuração e da distribuição socioespacial das redes de comunicação ${ }^{1}$ na região do Vale do Rio Pardo, parte-se do entendimento que a realidade é sempre dinâmica e,

\footnotetext{
*Mestrado em Desenvolvimento Regional (PPGDR/UNISC). Bolsista Capes II. https://orcid.org/0000-0001-54645953. Email:dianafa@unisc.br

**Doutorado em Geografia Humana (UFSC). Professor do Programa de Pós-Graduação em Desenvolvimento Regional da Universidade de Santa Cruz do Sul (UNISC). https://orcid.org/0000-0003-9470. Email:lls@unisc.br

***Doutorado em Desenvolvimento Regional pela Université du Quebéc à Rimouski, Canadá. Professora do Programa de Pós-Graduação em Desenvolvimento Regional da Universidade de Santa Cruz do Sul (PPGDR/UNISC). https://orcid.org/0000-0001-8162-578X. Email:grazielle@unisc.br
} 
ortanto, os conceitos devem dar conta desse movimento. Nesse sentido, recorremos a Milton Santos (2017, p.63), que nos diz que, no período atual, o espaço geográfico é formado por "um conjunto indissociável, solidário e contraditório de sistemas de objetos e sistemas de ações, não considerados isoladamente, mas como o quadro único no qual a história de dá". Assim, nos remete a pensar a comunicação, a partir do território, sob uma perspectiva crítica, quando visualizamos os objetos técnicos como suporte ao seu funcionamento, e o sistema de ações sendo responsáveis por sua execução, viabilização e condicionamento.

Devido à presença intensa das redes de suporte e de serviços nas dinâmicas sociais contemporâneas, a rede de comunicação impacta e, ao mesmo tempo, é conformada a partir de aspectos territoriais. Para tanto, encontramos, na Geografia Crítica de Milton Santos, a abordagem teórico-analítica adequada para realizar essa análise. O espaço, o meio técnicocientífico-informacional e o território usado são conceitos propostos por Santos que se inserem no contexto atual, cuja estrutura e uso são elementos que podem trazer ordem ou desordem na dinâmica do território. Nosso objetivo é analisar como ocorrem a configuração e a distribuição socioespacial das redes de comunicação no Vale do Rio Pardo, Rio Grande do Sul.

Para tanto, Corrêa (2005) nos remete e dá ênfase à ideia de particularidade, ao dizer que a região surge, no território, como um arranjo particular daquilo que compõe a realidade, uma instância particular, isto é, uma mediação entre o universal (os processos globais) e o singular (os lugares), e que, ao mesmo tempo, é vivida e compreendida de modo diferente pelos diversos grupos sociais. Nesse aspecto, a região que aqui se analisa - o Vale do Rio Pardo - corresponde à delimitação espacial do Conselho Regional de Desenvolvimento do Vale do Rio Pardo - CoredeVRP, que reúne 23 municípios, e cuja sede administrativa se localiza no município de Santa Cruz do Sul.

Essa região, definida, a priori, a partir de sua característica física, é geograficamente heterogênea e apresenta significativas diferenças e particularidades. Conforme pesquisa desenvolvida por Klarmann (1999), quando se observa o processo de formação dessa região e suas características socioculturais, políticas e econômicas, pode-se destacar a existência de três microrregiões distintas: a Norte, a Centro e a Sul. Essa regionalização também é utilizada para fins de planejamento do território regional.

\footnotetext{
${ }^{1}$ Neste artigo, o termo "redes de comunicação" refere-se tanto à presença de uma infraestrutura no território, quanto aos serviços que ela permite que se realizem, ou seja, as redes técnicas de suporte, redes técnicas de serviços e os meios de comunicação. As redes de suporte pesquisadas serão internet e telefonia móvel e, as de serviços, jornal, rádio e televisão.
} 
Conforme estimativa populacional de 2020 divulgada pelo IBGE, o Vale do Rio Pardo possui uma população de 409.431 habitantes, o que representa 3,58\% da população do Estado do Rio Grande do Sul. Números divulgados de um estudo feito pela Seplan (2015) indicam que $63 \%$ residem em áreas urbanas e $37 \%$ em áreas rurais. Localizada na região Centro-Oriental do Rio Grande do Sul, a sua extensão territorial abrange uma área de 13.171,7 Km² e uma densidade demográfica (2010) de 32,7 hab/ $\mathrm{km}^{2}$. O principal centro urbano é Santa Cruz do Sul, com uma população de 118.374 habitantes, seguido de Venâncio Aires, com 65.945 habitantes. A maior parte do conjunto dos municípios da região apresenta população inferior a 10 mil habitantes e o predomínio de domicílios localizados na zona rural.

Outra característica que imprime identidade à região e a particulariza, frente às demais do Estado, é a produção, beneficiamento e industrialização do tabaco, que tem seu principal complexo industrial em Santa Cruz do Sul. De acordo com Silveira et al. (2017), o Vale do Rio Pardo é a principal região do país que produz tabaco em folha por meio da agricultura familiar. O Vale do Rio Pardo apresenta uma distribuição bastante desigual da riqueza produzida entre os municípios que o integram, especialmente tomando como base o Produto Interno Bruto per capita referente ao ano de 2012, cujo PIB per capita regional é, moderadamente, inferior à média do Estado do Rio Grande do Sul; por outro lado, na região do Vale do Rio Pardo, as disparidades intrarregionais são acentuadas (SEPLAN, 2015).

O município de Santa Cruz do Sul é considerado o mais dinâmico da região, apresentando um PIB per capita de $\mathrm{R} \$ 42.737,00$, enquanto os municípios de Tunas e Encruzilhada do Sul apresentam os menores valores, respectivamente, um PIB per capita de $\mathrm{R} \$ 11.436,00$ e $\mathrm{R} \$$ 11.766,00. Em 2012, o maior PIB do Vale do Rio Pardo também era liderado por Santa Cruz do Sul, com aproximadamente $\mathrm{R}$ 5,1 bilhões, seguido por Venâncio Aires, com $\mathrm{R}$ 2 bilhões, sendo esses dois municípios responsáveis por $66,5 \%$ do PIB da região. Só o município de Santa Cruz do Sul respondia por 1,8\% do PIB do Estado (SEPLAN, 2015).

Outro indicador que atesta as desigualdades intrarregionais é o Índice de Desenvolvimento Socioeconômico (IDESE). A região do Vale do Rio Pardo apresentou, em 2015, um IDESE de 0,745, portanto, encontrando-se no nível médio ${ }^{2}$ de desenvolvimento. Já em relação ao Estado, o IDESE da região está um pouco abaixo do Rio Grande do Sul, que é de 0,754 (ATLAS SOCIOECONÔMICO DO RS, on-line). A posição do Corede-VRP no ranking dos Conselhos Regionais de Desenvolvimento (Coredes) está na $15^{\text {a }}$ colocação, com os indicadores de 0,717

\footnotetext{
${ }^{2}$ Considera-se a classificação do índice em alto (acima de 0,800), médio (entre 0,500 e 0,799) e baixo (menor de 0,499). Fonte: Seplan, 2015. Acesso em: 06 dez. 2020.
} 
(bloco educação), de 0,696 (bloco renda) e de 0,821 (bloco saúde), (FEE, 2016). Já, entre os municípios que compõem a região, há expressiva desigualdade em relação ao desenvolvimento socioeconômico: enquanto Santa Cruz do Sul apresentava um IDESE de 0,809, colocando-se entre um dos mais altos do Estado, os municípios de Herveiras e Passa Sete apresentavam, respectivamente, o IDESE de 0,608 e 0,606 (SEPLAN, 2015).

O estudo publicado pela Secretaria Estadual de Planejamento, Mobilidade e Desenvolvimento Regional (Seplan, 2015) traz algumas iniciativas promissoras na região e também reforça algumas questões que mereçam atenção especial, como a dependência da região em relação aos produtos do fumo; a poluição orgânica causada pelos dejetos domésticos nos rios; os baixos índices educacionais e os problemas na infraestrutura de comunicações, em que os municípios da região apresentam percentual de domicílios com acesso à internet e às telefonias fixa e móvel abaixo das médias estaduais.

Além desse estudo, as redes de comunicação foram destacadas como imprescindíveis para o desenvolvimento regional e, ao longo de todos os planos de desenvolvimento regional do Vale do Rio Pardo já realizados, figuraram como um tema prioritário no planejamento estratégico regional. Nesse processo recorrente de planejamento regional, realizado há mais de duas décadas, o diagnóstico regional, elaborado pelo Corede-VRP, aponta demandas relativas à infraestrutura de telecomunicações. Nesse contexto, buscaremos, nesse artigo, analisar como se apresentam a configuração e a distribuição espacial das redes de comunicação no Vale do Rio Pardo e seus reflexos para o desenvolvimento regional.

O artigo, além desta introdução, está constituído de outras três seções. Na primeira, apresentamos, ainda que brevemente, os referenciais teóricos e conceituais que orientam nossa análise, destacando a nossa compreensão e as interrelações entre os conceitos de território usado, rede de comunicação e desenvolvimento regional. Na segunda seção, verificamos a configuração e a distribuição das redes de comunicação no território regional. Na terceira seção, abordamos como se distribuem no território regional os meios de comunicação, evidenciando a existência na região de "lugares que comandam" e de "lugares que obedecem", a partir da atual configuração espacial dos fluxos de informação. Por fim, trazemos nossas considerações finais.

\section{Território Usado, Redes de Comunicação e Desenvolvimento Regional}

Na ciência regional, o aprofundamento teórico sobre o conceito de território está em permanente construção, uma vez que ele tem um conteúdo social, cuja mudança e processos 
são constantes. É fundamental ter esse olhar atento para o território, como um espaço geográfico historicizado e que é usado por um povo ou nação, mas, sobretudo, por atores sociais, empresas e instituições, cujas ações repercutem diretamente sobre o território. Essa perspectiva, reflete, por vezes, uma atuação em rede, que pode ser tanto institucional, organizacional ou até mesmo social, o que, na prática, pode implicar a potencialização ou exclusão, promovendo a ordem ou a desordem de um dado território. As redes, de forma isolada, não têm operacionalidade, no entanto, elas, sendo animadas por dinâmicas que vão desde a perspectiva local até a global, operam de forma tangível.

Assim, o território é visto a partir de um campo das práticas, das articulações espaciais e relações de poder e, buscando compreender as diversas manifestações que nele se dão, Santos (2017) nos diz que as características da sociedade e do espaço geográfico estão em relação com um estado determinado de técnicas. Desse modo, o conhecimento dos sistemas técnicos é fundamental para o entendimento das diferentes formas de estruturação, funcionamento e articulação dos territórios. "Cada período é portador de um sentido, partilhado pelo espaço e pela sociedade" (SANTOS, 2017, p. 171), sendo que a principal forma de relação entre o homem e a natureza é a técnica. $O$ teórico brasileiro define a história do meio geográfico em três etapas: o meio natural, o meio técnico e o meio técnico-científico-informacional. Sendo que o terceiro grande período, a partir dos anos 70, caracterizou-se pela revolução das telecomunicações.

Nessa perspectiva, em que os territórios são equipados para facilitar a circulação da informação, ganha força o conceito de território usado, quando Santos (1994, p. 15) diz que "é o uso do território, e não o território em si mesmo, que faz dele objeto da análise social". Complementando, ele diz que "o território são formas, mas o território usado são objetos e ações, sinônimo de espaço humano, espaço habitado" (SANTOS, 1994, p. 16). Para o geógrafo, o território usado compreende o contexto de grupos sociais diversos, a partir da ideia de espaço banal, de todas as empresas, instituições, pessoas, independentemente do tamanho e poder de cada um. E, para o autor, o conceito de espaço banal se opõe à noção de redes e justifica, de alguma forma, a expressão da verticalidade, fazendo referência à seletividade que as redes promovem no território.

No entanto, essa concepção sobre a relação entre rede e território, proposta por Santos (1994), expressa uma percepção de análise, já que ele faz referência tão somente à rede técnica presente no território. Silveira (2018) dirá que essa interrelação assume distintas dimensões, características e significados, que podem condicionar, promover e influenciar os processos de desenvolvimento regional, permitindo, assim, outras formas de análise e compreensão acerca 
dessa relação. Esse estudioso se apoia em autores como Painter (2009) e Haesbaert $(2002,2004)$, que fazem uma reflexão a partir do campo da geografia, em que ambos apresentam perspectivas de abordagem dessa relação, que oferece várias interpretações, desde uma falsa dicotomia ou possível interrelação entre redes e território.

A rede não cria um espaço dual, mas pode contribuir para a formação de desigualdades no território. Assim, é preciso ter presente o fato de que a rede, ao ligar pontos e lugares, é tanto um fator de solidariedade, coesão e integração regional quanto de transgressão, de desordem e de exclusão dos territórios, que opõem sua lógica funcional às malhas institucionais (OFFNER e PUMAIN,1996 citado por SILVEIRA, 2018). Nesse aspecto, a relação entre redes e território pode ser pensada a partir de uma dimensão relacional e interdependente, sobretudo quando a proposta é analisar processos de desenvolvimento regional, ou seja, desmistificando a ideia de que eles são opostos, separados e se negam.

No Brasil do século 20 , as redes de telecomunicações indicaram um período de investimentos e incorporação do progresso técnico no país, sob a égide do Estado. Conforme Dias (1996), a rede passou a integrar virtualmente todos os municípios na década de 80, no entanto, essa evolução apontou para um quadro desigual, tanto de acessos quanto do crescimento dos diferentes serviços. Perdura uma diferenciação entre os serviços de telecomunicações e as redes de suporte, que compõem a infraestrutura: a rede de comunicação é constituída e necessita de uma rede técnica de suporte, como satélite, fibra ótica, antenas de transmissão, por exemplo, que permitem o encaminhamento e o direcionamento dos fluxos; de outra parte, os serviços de comunicação são oferecidos a partir dessa infraestrutura, que são as redes de serviços, como a TV, a internet, o jornal, o rádio, o telefone, entre outros (DIAS, 1996).

No final da década de 90, ocorre a privatização das telecomunicações no país, com a Lei Geral das Telecomunicações ${ }^{3}$, que estabelecia os princípios do novo modelo. A privatização das telecomunicações, conforme Jurado da Silva (2015), contribuiu de forma decisiva para o aumento da quantidade de infraestrutura no território para esse fim, e, no caso das empresas de telecomunicações no território brasileiro, ficou evidente a influência que o espaço geográfico exerceu nas políticas de investimento, tendo suas atividades centradas em lugares com maior densidade técnica, econômica e populacional.

\footnotetext{
3 A Lei Geral das Telecomunicações, n. 9.472, de 16.7.1997, estabeleceu os princípios do novo modelo institucional do setor, criando e difundindo o papel da Anatel, os princípios do novo modelo tarifário, do Plano de Outorgas e Concessões e das diretrizes para a modelagem e venda de empresas estatais (TOLEDO JUNIOR, 2003, p. 97).
} 
Dessa forma, a temática das redes de comunicação ganha importância para a compreensão das desigualdades socioespaciais presentes no território, nas diversas escalas em que elas podem ocorrer, além da compreensão da dinâmica econômica e social de uma região. E aqui recorremos ao conceito de desenvolvimento regional proposto por Etges (2001), expresso como um processo em construção, amparado na potencialização de capacidades endógenas de um território, o que significa desenvolver-se a partir de suas próprias características e relações.

Assim, justamente pelo papel ativo que o território tem no desenvolvimento regional, é que ganha força o conceito de território usado, como categoria, para compreensão da configuração e da distribuição das redes de comunicação. Logo, o desenvolvimento regional não pode ser considerado sem levar em conta as condições políticas, econômicas, sociais, de estruturação e organização presentes em cada um dos 23 municípios de abrangência do CoredeVRP. Pensar esses conceitos numa dimensão relacional - e buscar compreender as implicações para a região e para as pessoas que nela vivem - é imprescindível para o desenvolvimento do território.

\section{Internet e telefonia móvel no Vale do Rio Pardo: difusão seletiva e desigual das infraestruturas comunicacionais}

Partimos para a análise da configuração e da distribuição da internet na região do Vale do Rio Pardo, que se constitui numa rede técnica de suporte, ou seja, é "o equipamento no território", pelo qual circulam os meios. A Anatel publica, mensalmente, a quantidade de acessos no Brasil relativos aos principais serviços de telecomunicações, como, por exemplo, Banda Larga Fixa, Telefonia Móvel, TV por Assinatura e Telefonia Fixa. Os dados na figura 1, abaixo, fornecidos à Anatel pelas próprias prestadoras, mostram a situação dos números de acessos de assinantes dos serviços de Banda Larga Fixa ${ }^{4}$ nos municípios do Vale do Rio Pardo. Também é informado o indicador da densidade desses serviços. Para os serviços de Banda Larga Fixa, o indicador é o número de acessos dividido pela quantidade de domicílios.

Na configuração e distribuição espacial dos dados sobre internet banda larga, evidenciase uma concentração maior de acessos em relação à população, em três municípios da região, que apresentam uma densidade acima de 20 acessos/100 habitantes, que são: Santa Cruz do Sul, com uma densidade de 27,51, seguido de Venâncio Aires, com uma densidade de 24 acessos e,

\footnotetext{
4 Banda larga é a conexão de internet que permite ao usuário navegar em alta velocidade. Fonte: <htttp://www.brasilbandalarga.com.br/bbbl/glossary>. Acesso em: 08 mar. 2021.
} 
ainda, Candelária, que apresenta 22,12 acessos/100 hab. Os dois primeiros municípios são também aqueles que apresentam o PIB per capita (2014) mais alto da região e, portanto, refletem como um indicador de maior poder aquisitivo da população.

Figura 1 - Quantidade de acessos à Banda Larga no Vale do Rio Pardo (2020)

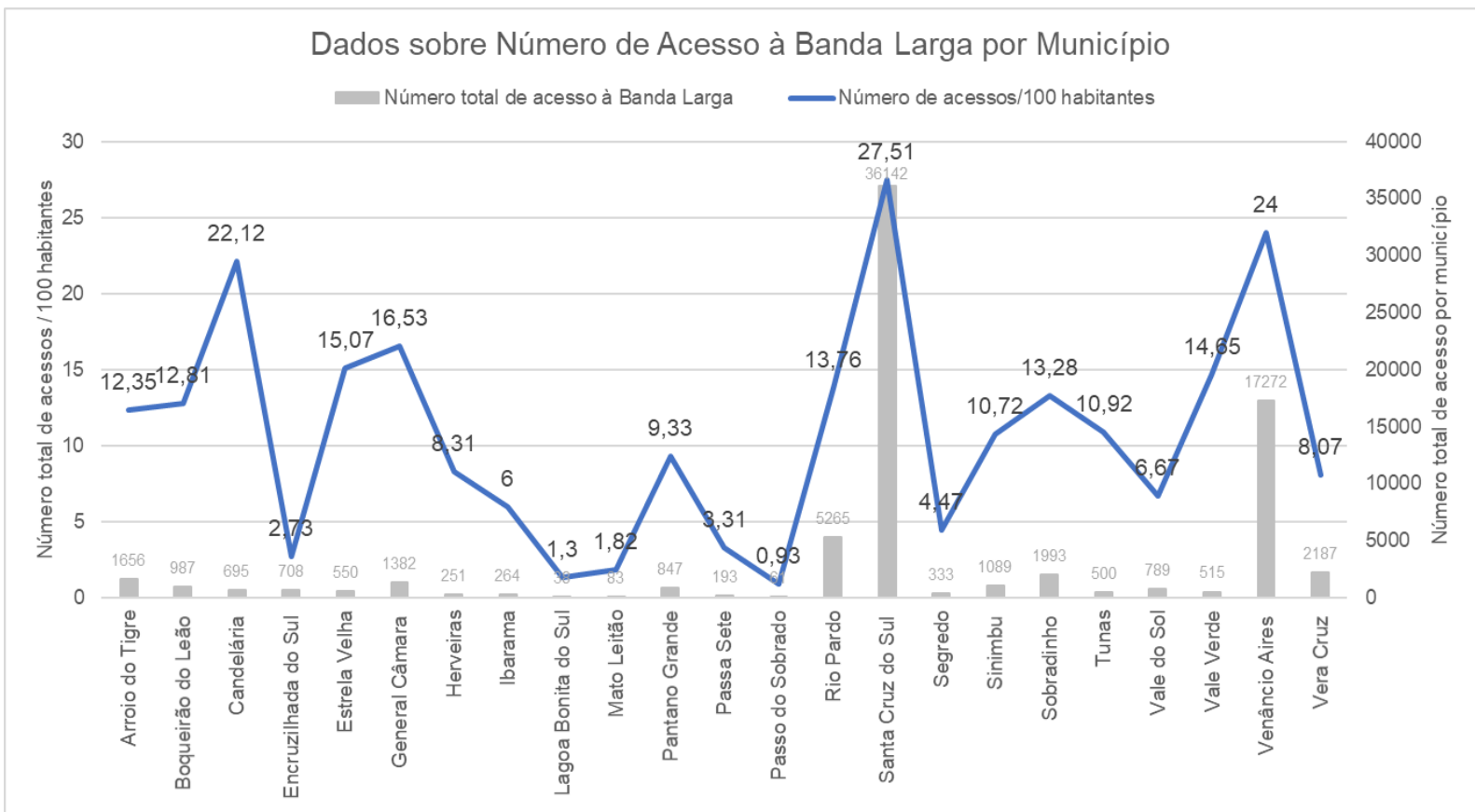

Fonte: www.teleco.com.br com dados da Anatel referentes a dez. 2020. Acesso em: 21 fev. 2021. Figura elaborada pelos autores.

Na faixa entre 20 e 10 acessos/100 habitantes figuram outros nove municípios, que são: Arroio do Tigre, Boqueirão do Leão, Estrela Velha, General Câmara, Rio Pardo, Sinimbu, Sobradinho, Tunas e Vale Verde. E, abaixo de 10 acessos/100 habitantes, encontra-se a maior parte de municípios, onze no total, como apresentado na figura 1.

Essa análise conjunta da espacialidade dos municípios da região nos mostra que somente 13\% dos municípios do Vale do Rio Pardo têm um maior acesso à internet (acima de 20 acessos/100 hab.), enquanto 39\% dos municípios têm um acesso intermediário (entre 20 e 10 acessos/100 hab.), e na grande maioria, ou seja, em 48\% dos municípios, a internet chega para um número menor de pessoas (menos de 10 acessos/100 hab.).

Essa distribuição espacial nos leva a algumas considerações, primeiro, a de que existe uma tendência, embora isso não seja absoluto em todos os municípios, na correlação entre o acesso à banda larga e o PIB per capita do município. Observamos que aqueles municípios que possuem uma quantidade maior de acessos de internet por habitantes também possuem um PIB per capita mais elevado, uma vez que esse indicador evidencia um maior poder aquisitivo e 
concentração de renda por parte da população desses municípios, e talvez isso se reflita no consumo/acesso aos serviços de internet.

Por outro lado, quando Silveira (2011, p. 155) se referia ao fato de que, associados ao momento histórico, os sistemas técnicos incidem sobre a divisão territorial do trabalho, que cria uma hierarquia entre os lugares e redefine, a cada momento da formação socioespacial, a capacidade de agir das pessoas, das firmas e das instituições, temos presente que, no território do Vale do Rio Pardo, os sistemas técnicos também explicam os acontecimentos. Cada um à sua época, ao tempo em que promovem uma seletividade entre os lugares, quando observamos que aqueles municípios com menor poder econômico não conseguem consumir e usufruir determinados tipos de serviços.

Entendemos que esse agir das pessoas, das empresas e das instituições, conforme se referiu Silveira (2011), perpassa por questões de ordem econômica, pela decisão ou não de empresas provedoras de internet, por exemplo, investirem em instalação de infraestrutura num determinado município. Ou seja, é norteado por questões dessa ordem, de capital, de lucro, de consumo e retorno. De um lado, as empresas e, de outro, a população que não pode acessar esses serviços, por não reunir condições financeiras para arcar com esses custos e consumir esse tipo de prestabilidade.

De outra parte, nos chama a atenção a ausência dos serviços de internet, seja pela falta/não interesse de oferta do serviço por parte de empresas no município, ou pela insuficiência de recursos da população para acessar esses serviços, como é o caso de Lagoa Bonita do Sul, na microrregião Norte do Vale do Rio Pardo, que figura como o município com menor percentual de acessos por habitante, atingindo a média de 1,30 acessos/100 hab.

Na microrregião Centro, é Mato Leitão que apresenta o menor índice, com uma média de 1,82 acessos/100 hab. e, na microrregião Sul, é Passo do Sobrado que aparece com o menor índice, 0,93 acessos /100 hab., seguido de Encruzilhada do Sul, com 2,73 acessos/100 hab., que é o maior município em extensão territorial da região, com uma área de $3.439 \mathrm{~km}^{2}$.

Aqui, recordamos Souza (2005), que, ao se referir a Milton Santos, diz que o território usado se constitui em uma categoria essencial para a elaboração sobre o futuro. A autora nos lembra que o uso do território se dá pela dinâmica dos lugares, sobretudo, no atual período histórico denominado por Santos de técnico, científico e informacional. E, quando olhamos para o período atual, vemos que o território do Vale do Rio Pardo incorpora conteúdos de ciência, técnica, informação e dinheiro e, assim, a expansão do meio técnico-científico-informacional, nas 
condições atuais, significa também a expansão da pobreza estrutural e da exclusão digital, uma vez que aquele também é social.

A atual configuração espacial da banda larga de internet nos dá uma fotografia da situação da região, que se apresenta dessa forma por diversas razões, envolvendo questões de ordem econômica, mas também geomorfológicas, já que temos municípios com relevo plano e outros montanhosos, o que pode se apresentar como uma barreira física em termos de acesso à infraestrutura e aos serviços. O contingente populacional também pode ser considerado, quando temos municípios com alta e baixa densidade demográfica, ou seja, maior e menor capacidade de consumo.

Aqui, não pretendemos dar respostas do porquê certos municípios figurarem com índices baixos de acessos de internet, em detrimento de outros, até porque necessitaríamos de uma maior investigação sobre essas motivações, mas, sim, traçar um panorama mais geral de como se apresenta esse acesso à internet por parte da população e dos municípios na região.

Dando sequência à análise, trazemos, na figura 2, um panorama sobre a quantidade de tecnologia de banda larga presente nos municípios do Vale do Rio Pardo, conforme dados extraídos do site da Teleco (2021, on-line), que apresenta dados sobre a Backhaul BL ${ }^{5}$ por município, com acessos, densidade, empresas prestadoras e a tecnologia presente, configurando-se nas conexões de internet via rádio, fibra ótica e leased line (LL).

Essa figura nos apresenta a espacialidade do número de tecnologia de banda larga presente nos municípios do Vale do Rio Pardo, que leva o nome de Backhaul. Ainda, conforme dados da Teleco (2021, on-line), a Backhaul é responsável pela interligação das estações de rádiobase (ERB); pela formação da rede; e pela capacidade para escoar o tráfego da ERB. Os tipos de Backhaul que existem são: rádio digital ponto a ponto; fibra ótica e linhas privativas. Essa explicação inicial se faz necessária para entendermos melhor como essas tecnologias de internet estão distribuídas na região.

\footnotetext{
${ }^{5}$ Backhaul é um termo em inglês que significa a porção de uma rede hierárquica de telecomunicações responsável por fazer a ligação entre o núcleo da rede, ou backbone, e as sub-redes periféricas. Fonte: <https://www.teleco.com.br/tutoriais.asp.> Acesso em: 08 mar. 2021.
} 
Figura 2 - Quantidade e tipos de tecnologia de Banda Larga no Vale do Rio Pardo (2020)

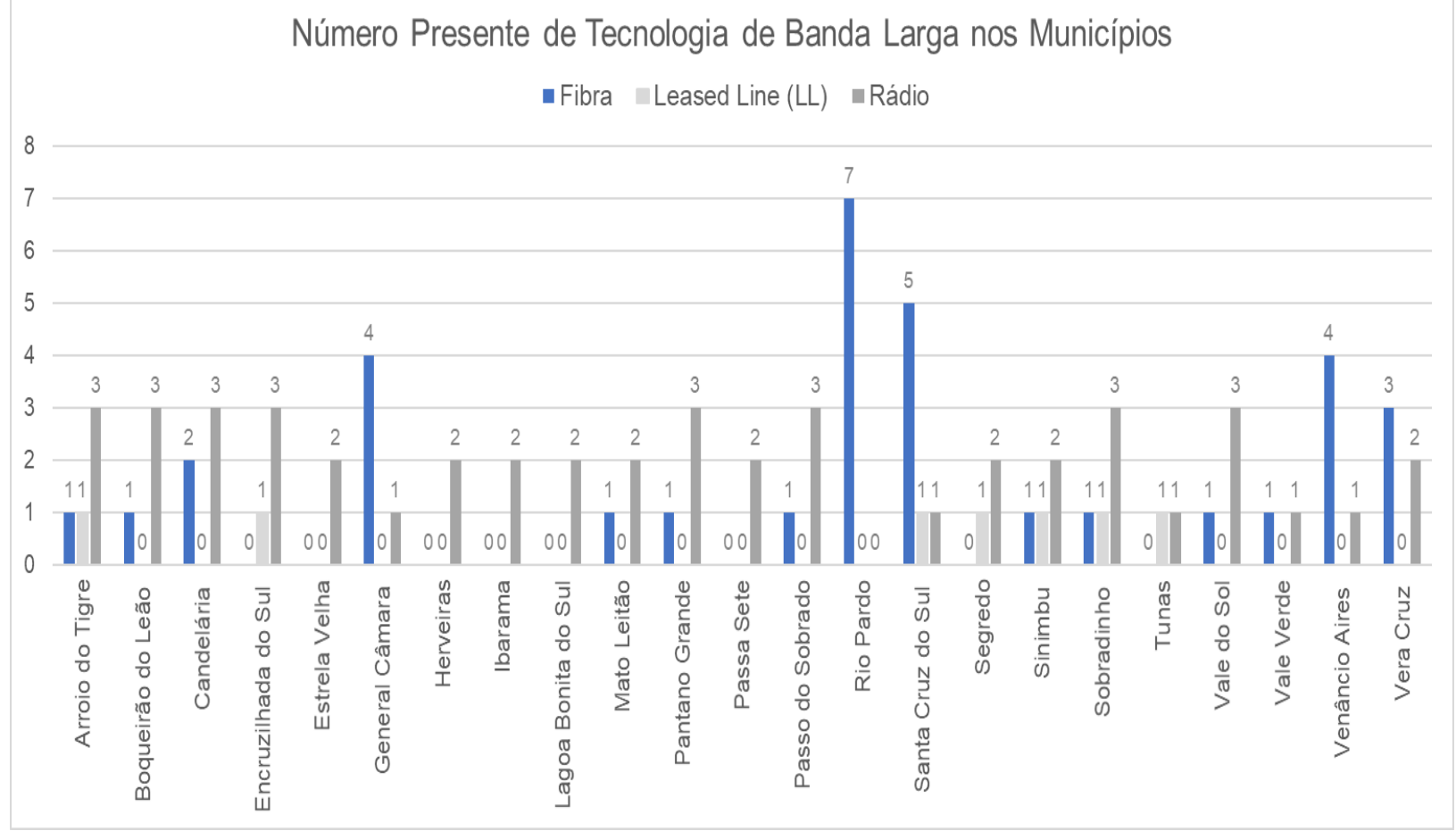

Fonte: www.teleco.com.br com dados da Anatel referentes a dez. 2020. Acesso em: 21 fev. 2021. Figura elaborada pelos autores.

É importante ter presente que, por trás de um sinal de internet, existem algumas variações de conexões, como a internet a Rádio, a Fibra Ótica ou Leased line (LL), o que pode mudar completamente a maneira como o usuário recebe o sinal de internet em seu domicílio, dispositivo móvel ou local de trabalho. Identificamos que as espacialidades dessas variações de internet - tecnologias presentes no território, bem como as empresas prestadoras desse serviço, se apresentam com um predomínio da conexão via rádio ${ }^{6}(47)$, seguida de fibra ótica ${ }^{7}(34)$ e leased line ${ }^{8}(7)$.

Nos municípios da microrregião Norte, fica evidente a oferta via rádio (17), seguida de leased line (4) e, em menor escala, a internet fibra ótica (2). Já na microrregião Centro, a oferta, tanto pela internet via rádio quanto fibra ótica, é equilibrada, aparecendo 16 ofertas para cada uma, seguida de leased line (2). E, na microrregião Sul, é a fibra ótica que dispara, com 16 ofertas, seguida de rádio (14) e leased line (1).

\footnotetext{
${ }^{6}$ Uma conexão de internet via rádio funciona sem nenhum tipo de fio chegando à residência, ela se propaga por meio de repetições de sinais que são feitas por diversas antenas posicionadas em lugares estratégicos.
${ }^{7}$ A conexão de internet via fibra ótica apresenta um meio de transmissão com um tráfego de dados com uma velocidade muito alta, já que a fibra consegue transmitir esse sinal por meio de reflexos de raio laser pelo cabo, o que favorece a sua capacidade transmissora.
${ }^{8}$ A variação de conexão denominada leased line (LL) implica uma linha alugada, é um circuito privado de telecomunicações entre dois ou mais locais fornecidos de acordo com um contrato comercial. Disponível em: <www.teleco.com.br>. Acesso em: 08 mar. 2021.


A figura 2 nos evidencia as diferenças de qualidade, estabilidade e velocidade que essas diferentes tecnologias de banda larga, disponíveis na região, apresentam. Esse também é um fator importante na geografia desigual das redes de comunicação no território regional. Os dados mostram que, se, por um lado, alguns municípios com elevado PIB possuem maior número de empresas oferecendo o serviço de fibra (reconhecido como mais veloz e estável), por outro lado, outros municípios, como General Câmara e Rio Pardo, embora apresentem PIBs menores, estão localizados próximos à configuração espacial da rede dessa infraestrutura na região, o que permite melhor oferta desse serviço.

Identificamos que a tecnologia de fibra ótica se destacou em municípios como Rio Pardo, Santa Cruz do Sul, Venâncio Aires e General Câmara, o que talvez se explique pelo fato dessa infraestrutura estar disponível junto aos eixos rodoviários das estradas, e as empresas que operam nesses municípios mudam para fibra ótica porque passam a ter esse serviço. Além disso, esses municípios estão sendo atendidos pela rede de fibra ótica que está sendo cabeada no Estado através ou nas margens desses eixos rodoviários, que conectam esses municípios, o que acaba favorecendo que elas tenham uma melhor condição logística e passem a operar em maior quantidade essas tecnologias.

Destacamos que pode haver certo atraso na atualização dos dados da Anatel, o que pode implicar a falta de registro de outras tecnologias que já estejam em uso nos municípios. Esses dados podem ter uma certa diferença em relação ao atual momento e a realidade dos municípios, tendo em vista que há atrasos na atualização dos dados das operadoras e das tecnologias usadas por essas operadoras na base de dados da Anatel.

No que se refere às empresas prestadoras de serviços de internet, verificamos que a operadora Ol está presente em todos os municípios do Vale do Rio Pardo, seguida da CLARO (78\%), VIVO (73\%), TIM (65\%), SOLINTEL (39\%), ABRINT ABRAMULT (17\%), SKY (4,34\%) e ALGAR TELECOM (4,34\%). A importância das empresas provedoras de internet fica evidente no contexto atual, em que o debate sobre os efeitos sociais e econômicos da transformação digital em curso está cada vez mais presente na agenda de governos e da sociedade civil, afetando diretamente a vida das pessoas, que passa pela necessidade de uma infraestrutura de conexão à internet de qualidade.

A diversidade de serviços possibilitada pela internet banda larga, atualmente, faz com que seja necessário pensar conjuntamente na expansão do serviço e no aprimoramento de sua qualidade. No entanto, a expansão do acesso à internet encontra empecilhos de várias ordens, desde aspectos socioeconômicos, tais como inexistência de infraestrutura de acesso adequada 
em comunidades de baixa renda em grandes centros urbanos, até questões geográficas, a exemplo do alto custo da instalação de infraestrutura em regiões de florestas ou montanhas, conforme dados apresentados pela TIC Provedores 2017 (Cetic, on-line).

Outro problema a ser considerado está associado às regiões menos favorecidas economicamente ou afastadas, que é a qualidade da internet: mesmo que haja conexão, a distância dos centros de distribuição do sinal e a infraestrutura mais precária colocam barreiras a um uso mais amplo da internet. Em um país com a dimensão territorial e os desafios sociais e econômicos do Brasil, a busca pela massificação da conexão à internet é permeada por diversas dificuldades. E, na região do Vale do Rio Pardo, não é diferente, já que o panorama apresentado revela baixa qualidade no sinal de internet, quando a maioria dos municípios tem conexão via rádio, o que pode ser dificultado por questões geográficas e de relevo, que fazem com que o sinal não chegue com a devida qualidade ao usuário final.

Uma conexão de baixa velocidade e alta latência leva a uma experiência on-line limitante, que não propicia um completo uso das possibilidades da internet: por exemplo, assistir a vídeos por streaming ou participar de jogos on-line se torna impraticável, senão impossível. Com isso, formas de lazer, atividades pedagógicas ou mesmo o acesso à informação e a serviços públicos são prejudicados pela baixa qualidade da conexão de internet, acentuando disparidades já existentes em termos de desigualdades regionais, sociais e econômicas, segundo a pesquisa TIC Provedores 2017 (Cetic, on-line).

Quando falamos em comunicação digital, os fluxos de comunicação se intensificam e passam a operar sob uma perspectiva em rede, e um desses avanços é a Lei de Acesso à Informação - Lei n. 12.527, de 2011, que regulamenta o direito de acesso à informação pública. Nesse aspecto, destacamos o artigo de Freitas e Brandt (2017) ${ }^{9}$, que traz considerações relevantes sobre a Lei de Acesso à Informação e suas repercussões no território, cuja pesquisa se deu em dois municípios do Vale do Rio Pardo, com o intuito de averiguar o que é feito pelas administrações públicas de Encruzilhada do Sul e Santa Cruz do Sul em seus portais institucionais, no cumprimento das exigências trazidas pela lei.

Aqui, lembramos que uma conexão instável e lenta no município é prejudicial e impõe, às gestões municipais, dificuldades operacionais, dada a crescente necessidade do cumprimento de obrigações fiscais via websites governamentais, como o caso que citamos acima. A dificuldade é

\footnotetext{
${ }^{9}$ FREITAS, Tamara Arend de; BRANDT, Grazielle Betina. A política de acesso à informação: considerações sobre a Lei de Acesso à Informação e suas repercussões no território. Território, Redes e Desenvolvimento Regional: Perspectivas e Desafios. Santa Cruz do Sul (RS), 13 a 15 de setembro de 2017.
} 
enfrentada tanto pelos governos municipais e câmaras de vereadores, por exemplo, que necessitam cumprir a lei junto ao portal da transparência, quanto pelo usuário cidadão, que muitas vezes não consegue ter acesso ao conteúdo pela baixa ou total falta de conectividade. Fizemos essa contextualização no intuito de mostrar o quanto a internet de qualidade é fator importante para o desenvolvimento dos municípios e, consequentemente, da região.

Entendemos que este é um setor que demanda investimentos significativos em infraestrutura e, muitas vezes, a decisão de ampliar o número de clientes pode assumir contornos de obra pública, envolvendo, por exemplo, o cabeamento de um bairro ou a substituição da rede metálica por fibra ótica e sua instalação domiciliar. Dessa forma, evidenciase a importância das empresas provedoras de internet que, atuando em menor escala, conseguem customizar soluções para uma clientela mais segmentada, podendo, assim, levar a conectividade para lugares mais remotos (TIC Provedores, 2017, on-line).

$E$, nesse contexto de tecnologia de operadoras presentes e ausentes num dado território, entendemos que o território usado é tudo aquilo que o constitui materialmente, isso é, as infraestruturas de redes técnicas de suporte e de serviços nas telecomunicações, mas também os fluxos de toda a ordem, incluindo os de informação. Desse modo, quando analisamos o fenômeno técnico, isso é, estamos fazendo um esforço para entender a constituição do território, ou seja, como, onde, por quem, por que, para que o território é usado (SILVEIRA, 2011, p. 155).

Ao final, partimos para a análise da telefonia móvel (Figura 3). A Anatel publica, mensalmente, a quantidade de acessos no Brasil relativos aos principais serviços de telecomunicações. Os dados abaixo - fornecidos à Anatel pelas próprias prestadoras - mostram a situação dos números de acessos à Telefonia Móvel. Também é informado o indicador da densidade dos serviços. Para o serviço de Telefonia Móvel, a densidade é o número de acessos dividido pela população. Os números de acessos por município para o serviço de Telefonia Móvel estão disponíveis somente a partir de janeiro de 2019. Por esse motivo, não são exibidos os dados por município caso seja selecionado um período anterior.

A figura 3 nos apresenta um panorama geral do total de celulares por município, bem como a densidade. Nesse cenário, destacam-se, justamente, os municípios-polo de cada microrregião e, também, aqueles que possuem maior densidade demográfica. No Norte, é Sobradinho que desponta com 83,89 celulares/100 habitantes; no Centro, é Santa Cruz do Sul, com um dado impressionante de 92,21 celulares/100 habitantes; e, no Sul, é a cidade histórica de Rio Pardo, com 73,45 celulares /100 habitantes. 
Figura 3 - Quantidade de celulares no Vale do Rio Pardo (2020)

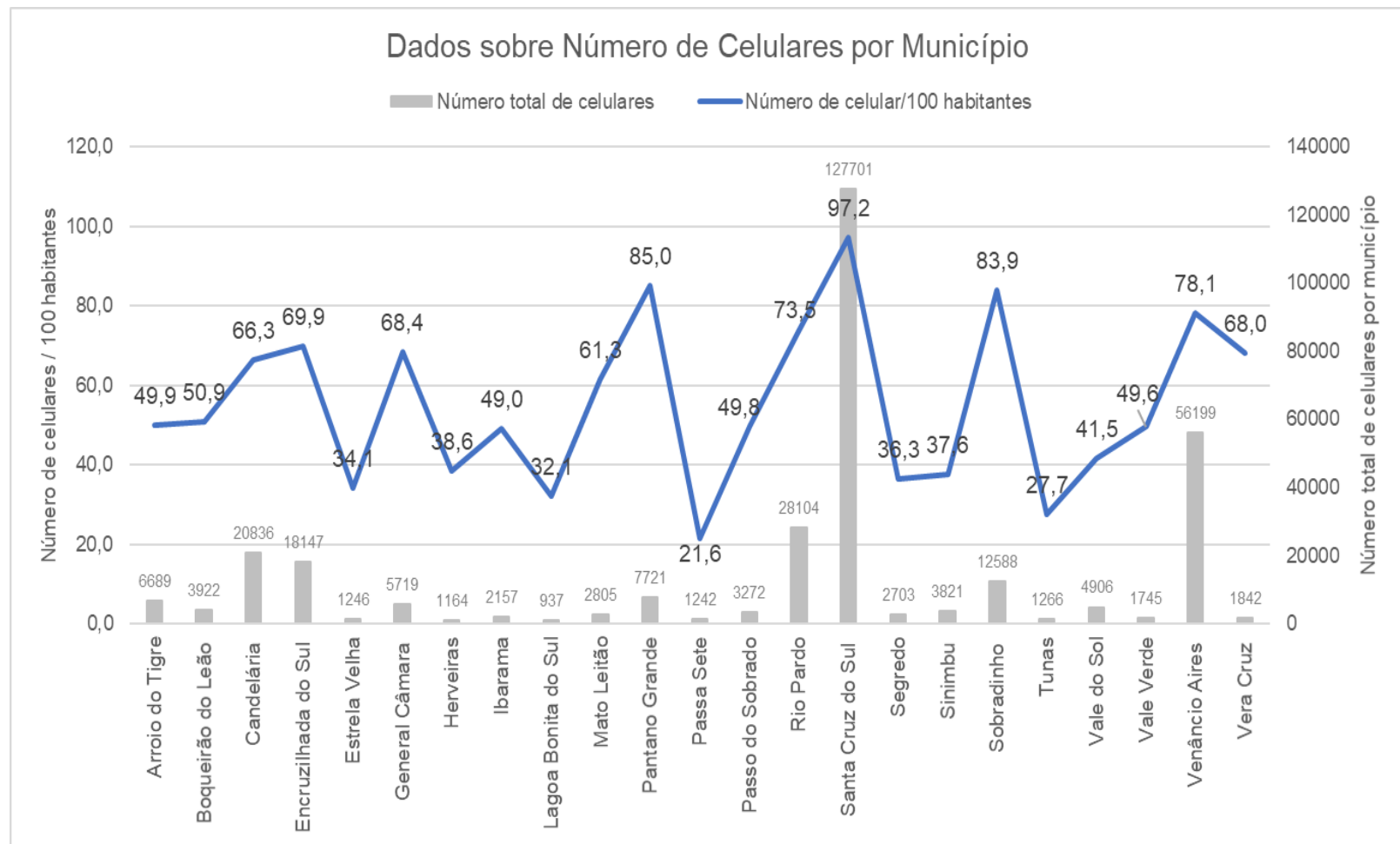

Fonte: www.teleco.com.br com dados da Anatel referente a dez. 2020. Acesso em: 21 fev. 2021. Figura elaborada pelos autores.

Daqueles municípios analisados na pesquisa, sobretudo na microrregião Norte, com exceção de Sobradinho, observamos uma baixa densidade nos demais grupos de municípios, que apresentam uma densidade abaixo de 50 celulares /100 habitantes, configurando os percentuais mais baixos em relação à região. Vejamos, Arroio do Tigre aparece na sequência, com 49,87; Ibarama, com 49,03; Segredo, com 36,31; Estrela Velha, com 34,14; Lagoa Bonita do Sul, com 32,08; Tunas, com 27,66; e o menor índice foi de Passa Sete, com 21,61.

Na microrregião Centro, com exceção de Santa Cruz do Sul, observamos um grupo de cinco municípios que apresentam densidade entre 80 e 40 e, depois, dois municípios abaixo de 40, que são Herveiras e Sinimbu. Na microrregião Sul, todos os municípios possuem densidade acima de 50 para 100/habitantes. As disparidades no acesso à telefonia móvel na região do Vale do Rio Pardo são evidentes, e, para além da questão econômica relativa à posse de um aparelho celular, por exemplo, interfere a infraestrutura no território com antenas que possibilitam o sinal ao aparelho.

Moreira (2012, p. 14) faz referência às estruturas de poder, em cujo bojo estão presentes os processos de inclusão e de exclusão, e a economia global se interessa em incluir, na sua rede, sociedades com alguma capacidade de consumo, ao mesmo tempo que exclui aquelas sem recursos. Relativo às empresas de telefonia que prestam serviço na região, existe um predomínio 
da operadora VIVO na maioria dos municípios, em alguns, chegando à oferta acima de $80 \%$ da carteira de clientes operando com a VIVO. Outras telefônicas também figuram, como a CLARO, a Ol e a TIM.

4 Os meios de comunicação no Vale do Rio Pardo: "lugares que comandam" e "lugares que obedecem", a partir dos fluxos de informação

A produção e a circulação da informação no território se dão pelas ações e reações entre os diferentes agentes sociais, instituições e empresas, e estes, por sua vez, se utilizam de diferentes meios de comunicação para fazê-lo. Lembramos que os meios de comunicação, objeto de análise desse tópico, só se viabilizam pelo uso e acesso a redes técnicas, e estas, sim, permitem a circulação da informação no território. São fatores que afetam a circulação no território: a infraestrutura técnica disponível, a qualidade do serviço e a diferença econômica dos usuários e consumidores. Uma vez apresentada a espacialidade das redes técnicas de suporte à internet e telefonia móvel, vamos analisar a configuração e a distribuição da rede técnica de serviços, ou seja, os meios de comunicação que circulam e se viabilizam através dessas redes.

Partindo do levantamento dos meios de comunicação existentes na região, com sede e produção de conteúdo nos municípios do Vale do Rio Pardo, verificamos a existência de 30 emissoras de rádio (AM, FM e Rádio Comunitária), 17 jornais (com diferentes circulações) e 4 emissoras de televisão (aberta, educativa e on-line). Verificamos, na figura 4, que, dos municípios do Vale do Rio Pardo, apenas doze possuem algum tipo de veículo de comunicação no município sede, e que onze municípios não têm a presença de nenhum tipo de veículo. Isso não significa que eles estejam descobertos dos serviços de mídia, mas indica que consomem informações advindas de outros lugares, que não são produzidas em seu município.

Nesse aspecto, percebemos que o município de Santa Cruz do Sul se destaca por sua real ou relativa condição de dinamismo, autonomia, desenvolvimento e centralidade, garantidos pela presença de órgãos oficiais administrativos e decisores, sedes e filiais de empresas e oferta de uma maior e mais especializada variedade de equipamentos e serviços, dentre eles os de mídia. Se considerarmos que somente o município de Santa Cruz do Sul possui, de forma isolada, sete emissoras de rádio, e a microrregião Centro contabiliza dezessete emissoras, este destaca-se como um lugar, um município e uma microrregião que comanda os fluxos de informação para os demais municípios da região. 
Figura 4 - Quantidade e tipos de meios de comunicação no Vale do Rio Pardo (2021)

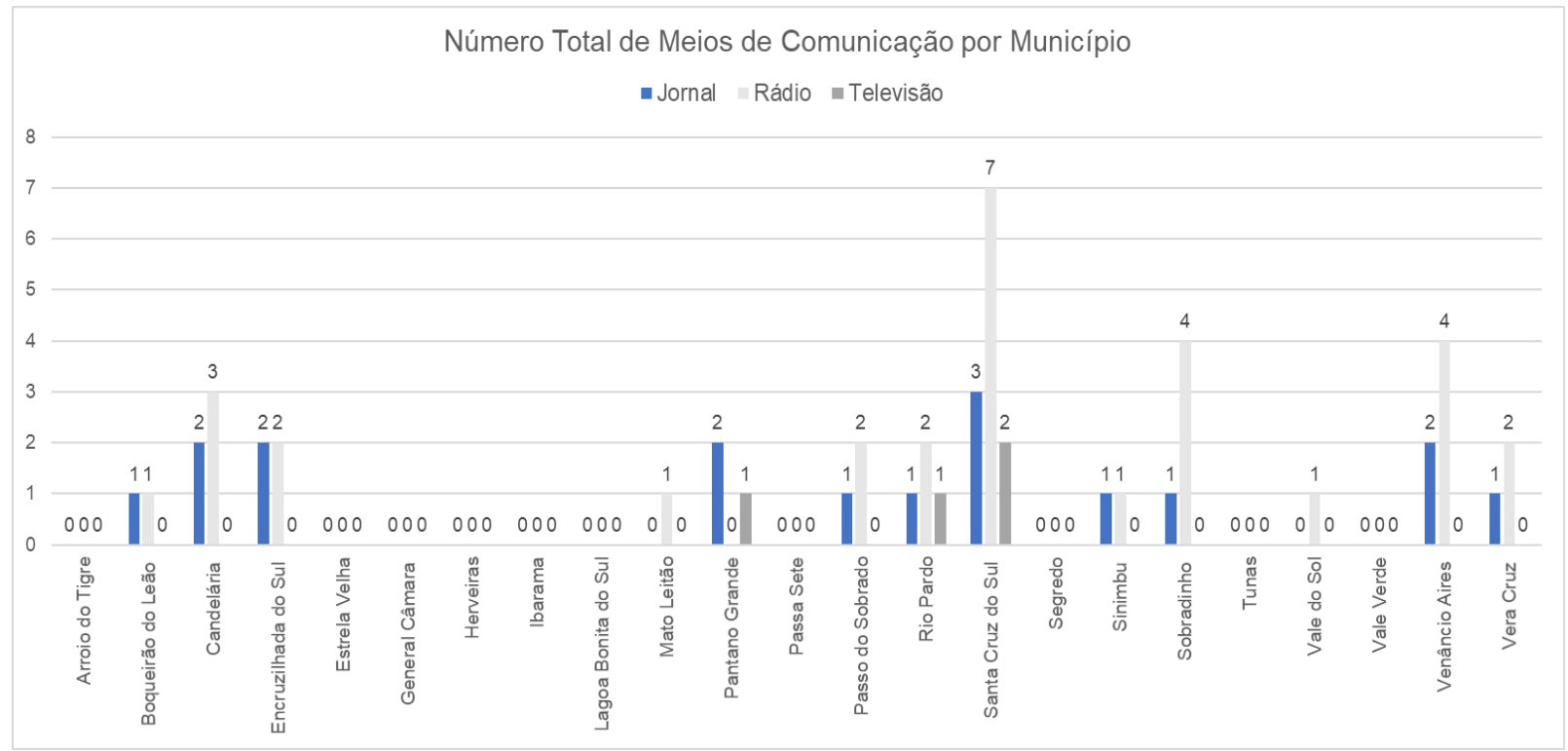

Fonte: www.adi-rs.org.br; Adjori/RS, on-line. Acesso em: 11 fev. 2021. Figura elaborada pelos autores.

Por outro lado, existem municípios de pequeno porte, com baixo dinamismo econômico e populacional e sem grande concentração urbana, que não têm sequer uma emissora de rádio comunitária. Esses municípios sem equipamentos de mídia são receptores de fluxo noticioso, mas nem sempre fonte de contrafluxo, figurando, assim, como verdadeiras colônias informativas, para utilizar as terminologias de Heloisa Herscovitz e Sonia Aguiar, na Enciclopédia INTERCOM (2010). As notícias, perpassando da escala mundial a local, chegam até esses municípios por meio de diferentes canais e origens, mas o que esses municípios emitem para si, para a região da qual fazem parte e para outros lugares, muitas vezes não é evidenciado, caracterizando-se como lugares que obedecem aos fluxos de informação. A figura 5 evidencia a desigualdade de comunicação entre os municípios e entre as microrregiões do Vale do Rio Pardo.

O veículo rádio é o que aparece com maior expressão no Vale do Rio Pardo, estando presente em doze municípios. As rádios de frequência FM estão em maioria, são 15 no total, seguidas das rádios comunitárias ${ }^{10}$, com 11 e, em menor escala, as rádios AM, com 4 apenas. Além da estrutura existente nos municípios-sede da região, também identificamos a existência de muitas unidades sucursais, em municípios vizinhos. O rádio aparece com muita expressão nos municípios da microrregião Centro, com 17 veículos, seguidos da microrregião Sul, com 9 e, depois, na Norte, com 4 veículos.

\footnotetext{
10 Fonte: AGERT. O serviço de radiodifusão comunitária foi criado pela Lei 9.612, de 1998, regulamentada pelo Decreto 2.615 do mesmo ano. Podem explorar esse serviço somente associações e fundações comunitárias sem fins lucrativos, com sede na localidade da prestação de serviços. Acesso em: 03 fev. 2021.
} 
Figura 5 - Quantidade de meios de comunicação por microrregião no Vale do Rio Pardo(2021)

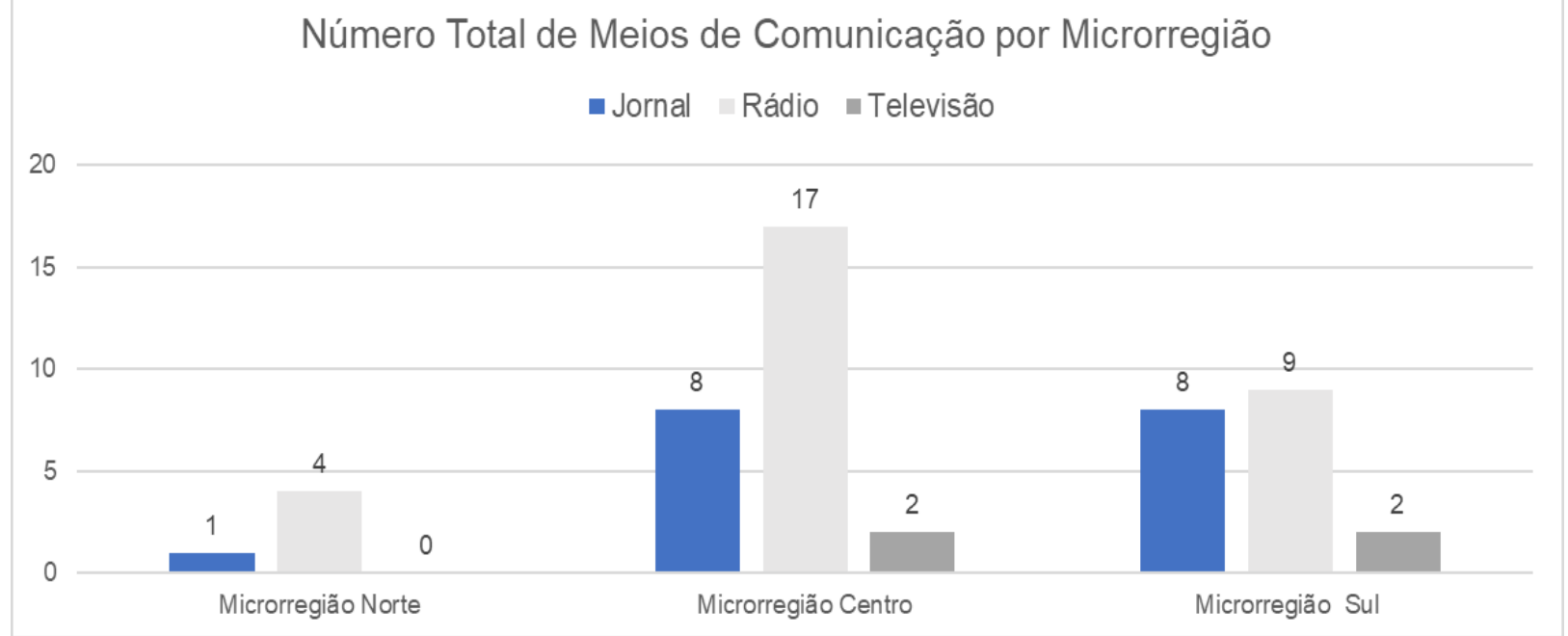

Fonte: www.adi-rs.org.br; Adjori-RS, on-line. Acesso em: 11 fev. 2021. Figura elaborada pelos autores.

A predominância do veículo rádio pode ser percebida com maior evidência na microrregião Norte, com a concentração desse meio de comunicação no município de Sobradinho, que comanda a informação através desse tipo de veículo naquela microrregião. As rádios com sede no município do Vale do Rio Pardo extrapolam a região geográfica, assim como os ouvintes da região também consomem conteúdos advindos de rádios de outras regiões, sobretudo limítrofes, em função do alcance e frequência. Esses dados nos mostram, com clareza, a importância e a relevância para região como um todo desse meio de comunicação, de baixo custo e fácil acesso, além de permitir, ao usuário, acessar e acompanhar a programação simultaneamente a outras atividades, sejam elas de trabalho, lazer, em ambientes diversos.

As emissoras de televisão concentram-se, na sua maioria, em Santa Cruz do Sul, analisadas TV aberta, educativa e on-line, e há uma em Pantano Grande e outra em Rio Pardo, com programação somente on-line. A RBS TV Santa Cruz do Sul ${ }^{11}$, também conhecida como RBS TV dos Vales, é uma emissora de televisão brasileira com sede no município de Santa Cruz do Sul. Retransmite a programação da Rede Globo para 64 municípios e gera programas locais, como o Jornal do Almoço. Opera no canal 6 (33 UHF digital). É uma das doze redes de transmissão regionais da RBS TV, que tem a central localizada em Porto Alegre. Em Santa Cruz do Sul, a emissora foi fundada em 28 de setembro de 1988. O canal era o único a cobrir a região com notícias locais até o surgimento de uma repetidora da TV Pampa Centro, de Santa Maria, em 2005.

\footnotetext{
${ }^{11}$ Fonte: https://pt.wikipedia.org/wiki/RBS_TV_dos_Vales. Acesso em: 02 mar. 2021.
} 
O mapeamento dos jornais impressos revelou a existência de apenas um jornal diário de abrangência regional, que é a Gazeta do Sul, localizada no município de Santa Cruz do Sul, e de outros dezesseis jornais com periodicidade semanal, bissemanal, trissemanal e até mensal, distribuídos no território do Vale do Rio Pardo. No caso dos jornais, entendemos que são um importante indicador de hierarquia dos centros de produção de mídia, bem como a sua área de influência, pois, mesmo sendo produzidos em determinado município, eles têm uma abrangência nos municípios do entorno.

Identificamos que a microrregião Centro e a Sul possuem o mesmo número de jornais impressos em circulação, totalizando oito em cada. E a microrregião Norte aparece com apenas um jornal ativo. A pesquisa buscou identificar quais desses jornais oferecem, ao leitor, a versão digital (on-line), considerando a praticidade e a instantaneidade do acesso. Praticamente todos eles disponibilizam conteúdo digital para os leitores, seja nos respectivos sites, portais de notícias, blogspot ou até mesmo em redes sociais, como Facebook e Instagram. Em alguns casos, o conteúdo é gratuito, em outros, o conteúdo é exclusivo para assinantes. Identificamos que alguns jornais fazem parte de grupos e pequenos conglomerados, que concentram, no seu escopo, diversas mídias, como jornal, rádio e portal de notícias, editoras, produtoras de eventos, e até mesmo TVs digitais.

\section{Considerações finais}

As redes de comunicação são imprescindíveis para o desenvolvimento regional. A análise das redes, sobretudo as de comunicações, é um instrumento valioso para a compreensão da dinâmica regional, porém, não abordada de forma isolada, mas sim na sua relação com a urbanização e a ruralização, com a divisão territorial do trabalho, com a dinâmica econômica dos municípios, mensurando a qualidade da infraestrutura e a prestação do serviço. No Vale do Rio Pardo, os sistemas técnicos também explicam os acontecimentos, cada um à sua época, ao tempo em que promovem uma seletividade entre os lugares, quando observamos que aqueles municípios com menor poder econômico não conseguem consumir e usufruir determinados tipos de serviços.

A análise que realizamos mostrou que a distribuição e a configuração espacial da internet e telefonia móvel na região não são uniformes. Os dados mostraram um número de acessos à banda larga, por município, a cada 100 habitantes, que se concentra nos municípios da 
microrregião Centro, e, quanto à telefonia móvel, nos municípios-polo de cada microrregião, Santa Cruz do Sul, Rio Pardo e Sobradinho.

Os dados apontam para uma distribuição desigual entre os municípios de maior e menor porte, bem como uma maior concentração de internet banda larga associada a municípios mais populosos e que apresentam PIB per capita mais elevado na região, ou seja, há uma correlação da oferta de serviços de internet, relacionada à densidade populacional e fatores de ordem econômica. Existe uma faixa de municípios que acessam os serviços, mas em menor escala e baixa qualidade, conforme verificado no tipo de tecnologia de banda larga presente no conjunto do território.

Pelo fato da rede possuir uma dimensão política e de poder, ela também envolve o acesso e o uso, o que Milton Santos (2017) atribui aos atores hegemônicos, que se servem de todas as redes e utilizam todos os territórios, reticulados e contraditórios, o que também se configura no Vale do Rio Pardo, ao passo que os demais ficam à margem do processo.

Essa mesma deficiência é revelada na telefonia móvel. Serão os municípios-polo de cada microrregião que vão se sobressair com os maiores acessos a cada 100 habitantes, aqui, novamente, configurada uma prevalência daqueles municípios mais populosos. Por outro lado, os dados fornecidos pela Teleco não nos dão um panorama da quantidade e da qualidade dos serviços prestados, ou seja, o equipamento no território, a distribuição das antenas e torres de telefonia que possibilitam ao usuário ter um sinal de qualidade, o que pode mascarar uma outra realidade empírica regional.

A atual configuração das redes técnicas de suporte impõe barreiras ao desenvolvimento da região, e não há previsão de que essa cartografia se altere, até porque, como destaca Dias (1996), as redes de telecomunicação só se materializam em função de decisões e estratégias, e a localização geográfica adquire um valor estratégico, mais seletivo. No caso da telefonia móvel, fica evidente que os investimentos de parte das operadoras de telefonia vão se dar, de forma estratégica, naqueles municípios com possibilidade de uma carteira maior de clientes, com retorno econômico, em detrimento àqueles que têm uma densidade populacional menor, que ficarão excluídos e à margem do acesso a esses serviços.

Na dimensão econômica, o espaço social é o lugar de reprodução da sociedade, é força produtiva, é produto consumido como mercadoria, mas também produtividade. O território usado incorpora técnicas e expressa funções econômicas, dizia Milton Santos (2017), tal qual se verifica no Vale do Rio Pardo, onde o território pressupõe uma forma de apropriação do espaço a partir de relações de poder, uma vez que, como os serviços de telecomunicações operam por 
meio da iniciativa privada, a política territorial das empresas se exime de um compromisso maior com os territórios.

Esse cenário se evidencia pelo fato da comunicação no Brasil ser regulada, o que impõe alguns limites ao território, e o mapeamento da distribuição e cobertura espacial da rede de serviços técnicos na região, especialmente da telefonia móvel, revela isso. A Anatel tem, por objetivo, a regulação de telefonia fixa, móvel, gerenciamento de contratos de concessão, fiscalização de serviços, realização de intervenções, controle e revisão tarifárias e prestação de serviços (Anatel, on-line) e, conforme regulação, as operadoras de telefonia têm a exigência de atender um raio de 30 quilômetros além da sede dos municípios com tecnologia móvel e fixa. Ou seja, de uma forma oficial, as operadoras não têm essa obrigação de chegar em cada parte dos municípios, mas sim, num raio urbano, o que contribui com a precária cartografia regional das redes de comunicação e explica, em parte, a falta de eco dos movimentos regionais junto às operadoras em audiências.

Essa desordem no uso do território, que serve somente a um número limitado de empresas, se constata na relação entre o mercado e o território, pois, além das empresas atuarem sob uma regulação que as favorece, elas se eximem de maior comprometimento na prestação do serviço, ficando evidente que o investimento maior vai recair naqueles municípios que sejam técnica e economicamente viáveis. É a influência do mercado no território que afeta e modifica as dinâmicas sociais e as relações humanas, a partir dos interesses singulares de atores hegemônicos. Santos (2017) previa essa seletividade causada pelas redes, e ela sendo global e local, única e múltipla, estável e dinâmica, faz com que a sua realidade, vista num movimento de conjunto, revele a superposição de vários sistemas lógicos, a mistura de várias racionalidades, cujo ajustamento, aliás, é presidido pelo mercado e pelo poder público, mas sobretudo pela própria estrutura socioespacial.

Assim sendo, infelizmente, o direito ao acesso à comunicação e à informação ainda não foi alcançado como direito fundamental, e não existem políticas públicas para a universalização desse acesso. Ao tempo em que as desigualdades regionais e territoriais, aliadas às desigualdades sociais e econômicas, somadas à baixa densidade populacional em alguns municípios, não tornam atrativos os investimentos nessa região, havendo uma concentração de investimentos em municípios com maior densidade populacional e poder econômico. Somado a isso, não há uma efetiva fiscalização e cobrança de investimentos por parte das agências reguladoras (Anatel). A soma de todos esses fatores faz com que a atual distribuição e configuração das redes de comunicação contribua para a formação das desigualdades no território. 
A presença intensa das mídias nas dinâmicas sociais contemporâneas, possível graças à rede técnica de suporte, impacta e, ao mesmo tempo, é conformada a partir de aspectos territoriais. Ao analisarmos a espacialidade das redes técnicas de serviços definidas neste trabalho, que são os jornais, as rádios e as TVs, verificamos que os meios de comunicação estão onde está o mercado, fruto de processo histórico da estruturação da comunicação no Brasil, pelo Código Brasileiro de Telecomunicações. Essa estruturação privilegiou o setor privado para exploração do setor de entretenimento, logo, o que aparece no Brasil, como um todo, vai se reproduzir também no Vale do Rio Pardo.

A análise configura uma concentração dos meios de comunicação na microrregião Centro, que possui os municípios mais populosos e também o PIB per capita mais elevado, em detrimento do restante da região. Dos 51 meios de comunicação com sede e produção de conteúdo nos municípios do Vale do Rio Pardo, 27 encontram-se em municípios da microrregião Centro, o que indica força publicitária, entre outros aspectos de mercado. A microrregião Sul aparece na sequência, com 19 e, por último, a Norte, com apenas 5 meios de comunicação. Dentre os meios pesquisados, o rádio figurou em maior número na região, 30 no total, sendo uma mídia com grande alcance social e territorial na região.

Apesar dos avanços tecnológicos que transformam a comunicação na atualidade, mantém-se o entendimento de que o desenvolvimento de um município ou região também guarda relações com o trabalho desenvolvido pela mídia. Assim, considerar as redes de comunicação nos estudos territoriais, fazendo um exercício analítico e reflexivo sobre as suas dinâmicas, é de extrema importância, uma vez que trazem consequências aos lugares e ao conjunto da região, sobretudo, no tocante ao seu desenvolvimento regional.

\section{Referências}

ADI-RS. Associação dos Diários do Interior do Rio Grande do Sul. Institucional. Disponível em: <https://adi-rs.org.br/ >. Acesso em: 09 fev. 2021.

ADJORI-RS. Associação dos Jornais do Interior do Rio Grande do Sul. Institucional. Disponível em: < http://www.adjorirs.net.br/>. Acesso em: 09 fev. 2021.

AGERT. Associação Gaúcha de Emissoras de Rádio e Televisão - Institucional. Disponível em: <https://www.agert.org.br/>. Acesso em: 03 fev. 2021.

AGUIAR, Sonia. Colonialidades da comunicação. In: ENCICLOPÉDIA INTERCOM de Comunicação, v. 1 Conceitos. São Paulo: INTERCOM, 2010. p. 228-229.

ANATEL. Agência Nacional de Telecomunicações. Apresenta informações gerais sobre a instituição. Disponível em: <https://www.anatel.gov.br/institucional/ >. Acesso em: 30 jun. 2020. 
ANATEL. Agência Nacional de Telecomunicações. Glossário. Disponível em: <https://www.anatel.gov.br/legislacao/glossario?catid=18.>. Acesso em: 30 jun. 2020.

ANATEL. Agência Nacional de Telecomunicações. Sistema de Controle de Radiodifusão (SDR). Disponível em:< https://sistemas.anatel.gov.br/srd/Consultas/ConsultaGeral/TelaListagem.asp?SISQSmodulo=5 243>. Acesso em: 10 fev. 2021.

ATLAS SOCIOECONÔMICO RIO GRANDE DO SUL. Porto Alegre: Secretaria de Planejamento, Governança e Gestão, 5. ed., jul/2020. Disponível em: <https://atlassocioeconomico.rs.gov.br>. Acesso em: 05 dez. 2020.

CGI.br/NIC.br, Centro Regional de Estudos para o Desenvolvimento da Sociedade da Informação (Cetic.br). Pesquisa sobre o setor de provimento de serviços de internet no Brasil- TIC PROVEDORES 2017. Disponível em:< https://cetic.br/pt/pesquisa/provedores/publicacoes/>. Acesso em: 10 fev. 2021.

COREDE-VRP. Conselho Regional de Desenvolvimento do Vale do Rio Pardo. Institucional. Disponível em: <coredevrp.org.br>. Acesso em: 15 dez. 2020.

COREDES RS. Conselhos Regionais de Desenvolvimento do Rio Grande do Sul. Institucional. Disponível em: < https://forumdoscoredes.org.br/>. Acesso em: 06 mar. 2021.

CORRÊA, Roberto Lobato. Entrevista com o Prof. Dr. Roberto Lobato Corrêa. Revista Discente Expressões Geográficas. Florianópolis-SC. $2005 . \quad$ Disponível em: <http://www.geograficas.cfh.ufsc.br/arquivo/ed01/entrevista.pdf>. Acesso em: $01 \mathrm{dez} .2020$.

DIAS, Leila Christina. Redes eletrônicas e novas dinâmicas do território brasileiro. In: CASTRO, I. E. de; GOMES, P.C. da C; CORRÊA, R.L. (org.). Brasil: questões atuais da reorganização do território. Rio de Janeiro: Editora Bertrand Brasil, 1996. p. 115-144.

ETGES, Virginia Elisabeta. A região no contexto da globalização: o caso do Vale do Rio Pardo. In: VOGT, O.P.; SILVEIRA, R.L.L. da (org.). Vale do Rio Pardo: (re)conhecendo a região. Santa Cruz do Sul: EDUNISC, 2001. p. 351-366.

FIORI, Tomás Pinheiro. Principais resultados do IDESE 2016. Porto Alegre: Secretaria de Planejamento, Orçamento e Gestão. Departamento de Economia e Estatística. Nota Técnica n.12, 02 out. 2019. Disponível em: <https://dee.rs.gov.br/upload/arquivos/202004/22153608-nt-12idese.pdf>. Acesso em: $13 \mathrm{dez} .2020$.

FREITAS, Tamara Arend de; BRANDT, Grazielle Betina. A política de acesso à informação: considerações sobre a Lei de Acesso à Informação e suas repercussões no território. In: VIII SEMINÁRIO INTERNACIONAL SOBRE DESENVOLVIMENTO REGIONAL - TERRITÓRIO, REDES E DESENVOLVIMENTO REGIONAL: PERSPECTIVAS E DESAFIOS, 2017, Santa Cruz do Sul. Anais [...] Santa Cruz do Sul, 13 a 15 de setembro de 2017. p.1-23.

HERSCOVITZ, Heloíza Golbspan. Contrafluxos da Informação. In: ENCICLOPÉDIA INTERCOM DE COMUNICAÇÃO. V. 1 Conceitos. São Paulo: INTERCOM, 2010. p. 329-330.

IBGE. INSTITUTO BRASILEIRO DE GEOGRAFIA E ESTATÍSTICA. Disponível em: <www.ibge.gov.br>. Acesso em: 05 dez. 2020.

JUNIOR, Rubens de Toledo. Telecomunicações e Uso do Território Brasileiro In: SOUZA, M.A.A. de. (org.). Território Brasileiro. Usos e Abusos. Campinas: Edições Territorial, 2003. p. 93-107.

KLARMANN, Herbert. Região e identidade regional: um estudo da espacialidade $e$ representatividade regional do Vale do Rio Pardo. 1999. 147 f. (Programa de Pós-Graduação em 
Desenvolvimento Regional - Mestrado) - Universidade de Santa Cruz do Sul, Santa Cruz do Sul, 1999.

MOREIRA, Sonia Virginia. Por que Geografias, no plural, para a Comunicação? In: MOREIRA, Sonia Virginia. Geografias da comunicação: espaço de observação de mídia e de culturas. São Paulo: INTERCOM, 2012.p.09-20.

RBS TV. In: WIKIPÉDIA: a enciclopédia livre. Disponível em: <https://pt.wikipedia.org/wiki/RBS_TV_dos_Vales>. Acesso em: 02 mar. 2021.

SANTOS, Milton. A Natureza do Espaço: Técnica e Tempo, Razão e Emoção. 4. ed. São Paulo: Edusp, 2017.

SANTOS, Milton. O retorno do território. In: SANTOS, Milton; SOUZA, Maria Adélia Aparecida de; SILVEIRA, Maria Laura (org). Território: Globalização e Fragmentação. 4. ed. São Paulo: Hucitec ANPUR, 1994. p. 15-20.

SECRETARIA DO PLANEJAMENTO, MOBILIDADE E DESENVOLVIMENTO REGIONAL (SEPLAN). Perfil Socioeconômico Corede Vale do Rio Pardo. Governo do Estado do Rio Grande do Sul. Secretaria do Planejamento, Mobilidade e Desenvolvimento Regional. Departamento de Planejamento Governamental. Porto Alegre, nov. 2015. Disponível em: $<$ https://planejamento.rs.gov.br/upload/arquivos/201603/17095302-perfis-regionais-2015vale-do-rio-pardo.pdf >. Acesso em: 05 dez. 2020.

SILVA, Paulo Fernando Jurado da. Geografia das Telecomunicações no Brasil. São Paulo: Cultura Acadêmica, 2015.

SILVEIRA, Maria Laura. O Brasil: Território e Sociedade no início do século 21 - A história de um livro. ACTA Geográfica. Edição Especial "Cidades na Amazônia Brasileira", Boa Vista, Roraima, p. 151-163, 2011. Disponível em: <https://revista.ufrr.br/actageo/article/view/556>. Acesso em: 21 jan. 2021.

SILVEIRA, Rogério Leandro Lima da et al. Policentrismo, Áreas Urbanas Funcionais (FUAs) e Dinâmica Territorial: um estudo exploratório desde a região do Vale do Rio Pardo-RS-Brasil. Redes, Santa Cruz do Sul, n. 1, p. 184-217, jan. 2017.

SILVEIRA, Rogério Leandro Lima da. Território, Rede e Desenvolvimento Regional-Notas para discussão. In: SILVEIRA, R.L.L.da; FELIPPI, A.C.T. (org.). Territórios, Redes e Desenvolvimento Regional: Perspectivas e Desafios. Florianópolis: INSULAR, 2018, p. 231-252.

SOUZA, Maria Adélia Aparecida de. Milton Santos - O retorno do território. In: OSAL: Observatório Social de América Latina, ano 6, n. 16, jun. 2005, Buenos Aires: CLACSO, 2005. Disponível em: <http://bibliotecavirtual.clacso.org.ar/ar/libros/osal/osal16/D16Santos.pdf.> Acesso em: 20 jan. 2021.

TELECO. INTELIGÊNCIA EM TELECOMUNICAÇÕES. Disponível em: <https://www.teleco.com.br/ $>$ Acesso em 10 fev. 2021. 